\title{
Designing An Interactive Program To Simulate Economic Growth Models For College Education
}

Mohamad Shaaf, University of Central Oklahoma, USA

\begin{abstract}
Using Excel, an interactive program is designed to simulate the Solow and endogenous growth models to facilitate the understanding of these models for students of growth theory and macroeconomics.
\end{abstract}

\section{INTRODUCTION}

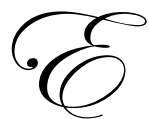

conomic growth models in the form of equations and graphs were developed first by two British economists Harrow (1939) and Domar (1946). This setup is based on the fact that on the demand side of the economy investment is an important determinant of the level of output, and the supply-side investment is an important determinant of the rate of increase of potential output by increasing the capital stock. Accordingly, there will be one investment path along which the capital stock will be fully employed, with the level of demand just sufficient to absorb the total output produced by the capital stock. In this framework equilibrium growth requires that both the labor force and the capital stock be fully employed as the economy grows.

A similar setup was designed by the pioneering work of Robert Solow $(1957,1960)$ as the foundation of further development and advances in growth models. In the Solow setup, production function is in the form of constant return to scale, and is subject to the law of diminishing return; saving rate, depreciation rate, population growth, and, most importantly, technological change as exogenous variables. One of the major criticisms of Solow's model is that technology as the only permanent source of growth is exogenous. To remedy this flaw, several endogenous growth models were developed that explain the growth within the model, with constant return instead of diminishing return production function.

The purpose of this research is to develop numerical and graphical simulations of the Solow growth model that can be extended to endogenous growth models, by changing the parameters of the setup. The simulation is based on the equations, and the interaction of exogenous and endogenous variables with their correspondent parameters. The equations and their endogenous variables are solved by the interaction of exogenous variables within the limitations of the parameters. The change in each parameter and exogenous variable results in changes in the steady state all endogenous variables.

An excel spreadsheet is utilized to develop the equations and calculate their interrelationship based on the structure and the properties of the model. The model is simulated by changes of each exogenous-variable and each parameter in the system of equations in the model, as well as computing and showing the endogenous variables in their boxes and simultaneously in the graphs. The changes in magnitude are seen in the boxes, and shown in the graphs and corresponding numbers of the variables in the model. This simulation exercise can be used for undergraduate courses in Economic Growth, and Macroeconomic courses.

The structure of Harrow (1939) and Domar (1946), that of Solow, and that of endogenous growth models are explained in the following section. Next, the excel formulation and simulation of Solow and that of the endogenous growth model are presented. The final section provides conclusions. The excel setup for the models will be attached, and can be received free of charge by email request. 


\section{STRUCTURE OF THE GROWTH MODELS}

The Harrow (1939) and Domar (1946) setup has a fixed-coefficients technology, so that a units of labor, L, and $\mathrm{v}$ units of capital, $\mathrm{K}$, are needed to produce one unit of output $\mathrm{Y}$, then the production function can be explained by equation (1), and Figure 1.

$$
Y=\min \left[\frac{K t}{v}, \frac{L t}{\alpha}\right]
$$

The production isoquants in Figure 1 showing levels of output $\mathrm{Y}$ are right-angled with corners along the ray from the origin, with the slope of v/a For $\mathrm{Y} 1=1$, we can measure $\mathrm{K}=\mathrm{v}$, and $\mathrm{L}=\mathrm{a}$ as shown in Figure 1. To maintain full employment of capital in this setup, output, $\mathrm{Y}$, and investment, I, must grow at the rate of s/v. This is,

$$
\Gamma Y=\Gamma I=s / v
$$

Here $\Gamma$ represents the rate of growth.

The Solow setup with the production function in the form of constant return to scale and diminishing return, with saving rate, depreciation rate, population growth, and most importantly technological change as exogenous can be presented in the form of equation (3) or (4) and Figure 1.

$\mathrm{y}=\mathrm{f}(\mathrm{k})$, or

$\mathrm{y}=\mathrm{A} \mathrm{k}^{\mathrm{a}}$

Where $\mathrm{y}$ is output/labor ratio, and $\mathrm{k}$ is capital/labor ratio, $\mathrm{A}$, and a are the parameters of the model, and a $<1$ to maintain the diminishing return.

The aggregate supply of output per worker, $y$, is divided into consumption per worker, $c$, and saving per worker of sy, since the model assumes that each period people save a fraction s of their income, and consume a fraction, 1-s, of their income. That is,

$\mathrm{y}=\mathrm{c}+\mathrm{sy}$

The aggregate demand in this model comes from consumption per worker, c, and investment per worker, i, as follows

$\mathrm{y}=\mathrm{c}+\mathrm{i}$

The steady state of the model for each period is the equality of the aggregate supply with that of aggregate demand, i.e., equations (5) and (6), or

$\mathrm{i} *=\mathrm{sy}^{*}=\mathrm{s} \mathrm{f}\left(\mathrm{k}^{*}\right)$

That is, steady state investment per worker, $\mathrm{i}^{*}$, equals steady state saving per worker, sy*, at the steady state level of capital per worker, $\mathrm{k}^{*}$, and steady state output per worker, $\mathrm{y}^{*}$.

The impact of a change in the saving rate, $\mathrm{s}$, and/or a change in population growth, $\mathrm{n}$, results in a temporary change in the rate of growth of output to a new steady state, and not a permanent growth of output. The sole source of permanent growth of the model is exogenous technological change. Solow's model also introduces the golden rule of capital accumulation as the rate of saving that maximizes the steady-state consumption, $\mathrm{c}^{*}$. This maximization is the objective function of the model. This goal can be achieved where marginal productivity of 
capital equals to the sum of the rate of depreciation of capital, $d$, rate of population growth, $n$, and the efficiency of labor, g. That is, $M P K=\mathrm{d}+\mathrm{n}+\mathrm{g}$.

This model with production function, $y$, investment function, $i$, and sy function is represented in Figure 2 . The steady state capital per worker of $\mathrm{k}=25$ is where $\mathrm{i}^{*}=\mathrm{sy}^{*}$, and represents the golden rule of $\mathrm{k}^{* *}, \mathrm{y}^{* *}, \mathrm{c}^{* *}$, and $i^{* *}$. Here, $* *$ is the sign of the golden rule. If the steady state capital labor ratio, $\mathrm{k}^{*}$, is below the golden rule capital labor ratio, $\mathrm{k}^{* *}$, an increase in saving rate, $\mathrm{s}$, moves the economy towards the golden rule $\mathrm{k}^{* *}$. Inversely, if the steady state capital labor ratio, $\mathrm{k}^{*}$, is above the golden rule capital labor ration, $\mathrm{k}^{* *}$, a reduction of the saving rate moves the economy towards the golden rule, keeping other parameters constant.

The model has a tendency approaching towards the steady sate. This tendency can be explained by the phase diagram that shows the impact of the changes of $\mathrm{k}$ on the growth rate of $\mathrm{k}$ as follows

$$
\Gamma k=k
$$

Here, $\Gamma$ is the rate of growth. A typical phase diagram is shown in Figure 3. Accordingly, the economy will move toward steady state $\mathrm{k}^{*}$ where $\Gamma \mathrm{k}=0$, from any initially given $\mathrm{k}$. To the left of $\mathrm{k}^{*}, \Gamma \mathrm{k}>0$ and $\mathrm{k}$ is increasing. To the right of $\mathrm{k}^{*}, \Gamma \mathrm{k}<0$ and $\mathrm{k}$ is decreasing. At $\mathrm{k}^{*}, \Gamma \mathrm{k}=0$, so that the economy stays at $\mathrm{k}^{*}$, where the system is stable. Thus, at $\mathrm{k}^{*}=25, \Gamma \mathrm{k}$ approaches zero, that corresponds to the steady state $\mathrm{k}^{*}$.

The endogenous growth models explain output growth within the model, with production function of constant return instead of diminishing returns to remedy the diminishing return flaw of the Solow model. A typical endogenous growth model is in the form of equation (9) and Figure 4.

$\mathrm{Y}=\mathrm{A} \mathrm{K}$

Where, $\mathrm{Y}$ is the aggregate level of output, $\mathrm{K}$ is a broad measure of the stock of capital, including physical capital of plants and equipment and human capital, and $\mathrm{A}$ is a constant measuring the amount of output produced for each unit of capital. The endogenous model can have unlimited growth as long as

$\mathrm{sA}>\mathrm{d}$

That is, the economy continues to grow as long as multiplication of saving rate and $\mathrm{A}$ is larger than the rate of depreciation, d.

Similarly, the phase diagram of the endogenous model shows the impact of the changes of $\mathrm{K}$ on the growth rate of $\mathrm{K}$, is shown in equation (11)and Figure 5.

$$
\Gamma K=K
$$

Notice that in this phase diagram is linear that implies the growth is limitless because a higher level of capital results in a higher growth of capital.

\section{EXCEL FORMULATION AND SIMULATION OF SOLOW AND ENDOGENOUS MODELS}

An excel spreadsheet is utilized to formulate the equations and their interrelationship based on the structure and the property of the Solow model. That formulation also extended to endogenous growth models, by changing the parameter of ' $a$ ' in equation (9) to be equal to one. The production per worker, saving per worker, consumption per worker and investment per worker functions of the Solow model equation are determine from the solution of equations (4), (7), (8), and (11) with parameters of s, A, and a.

A change in each of these parameters can change the steady state of endogenous variables of $\mathrm{k}^{*}, \mathrm{y}^{*}, \mathrm{i}^{*}, \mathrm{c}^{*}$, and growth of $\mathrm{k}$ (Phase Diagram) in the spreadsheet, and their corresponding Figures. For simplicity the worksheet 
assumes population growth, $\mathrm{n}$, and labor efficiency, $\mathrm{g}$, equal to zero. That is, $\mathrm{n}=\mathrm{g}=0$. In the Solow model, with diminishing return, the condition of $a<1$ in equation (4) must be met, as shown in Figure 2. With $a=1$, the production function changes into a constant return, and converts into an endogenous model, similar to Figure 4.

The resulting solutions of endogenous variables of equations and their corresponding graphs are shown in the spreadsheet, Table 1. The model simulation is conducted by changes of each exogenous-variable and each parameter. These changes result in changes in the systems of equations in the model, computing and showing the endogenous variables in their boxes in numbers, and correspondingly and simultaneously, the changes would be shown in the spreadsheet graphs. For example, a change in the saving rate, s, in the Solow model results in changes in the saving function, sy*, steady state capital-labor ratio, $\mathrm{k}^{*}$, consumption-labor ratio, $\mathrm{c}^{*}$, and output-labor ratio, $y^{*}$, in the table and correspondingly on the graphs. These simulations for Solow model are shown in Figures 6 and 7. Similarly, a change of the parameter ' $a$ ' from $\mathrm{a}=0.5$ to $\mathrm{a}=1$ causes a change in the model to an endogenous one that has linear production function and phase diagram.

\section{CONCLUSIONS}

Using Excel software with its graphical capability, this study simulates the Solow and endogenous growth models to facilitate the understanding of these models for students of growth theory and macroeconomics. This exercise can show how a change in a parameter of each model changes the numbers and graphs of the production function, saving function, investment function, and phase diagrams, as well as the steady states endogenous in those models.
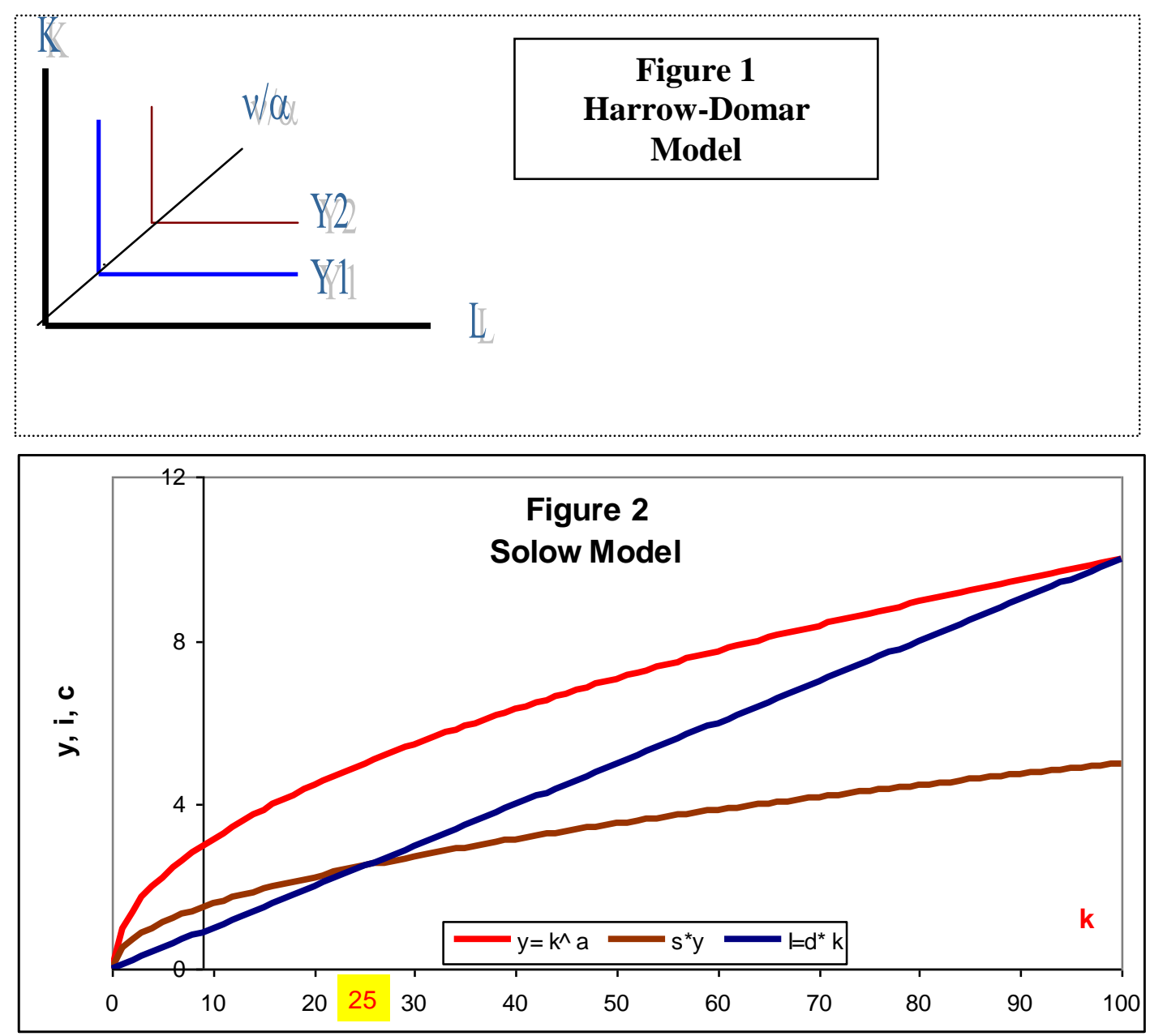

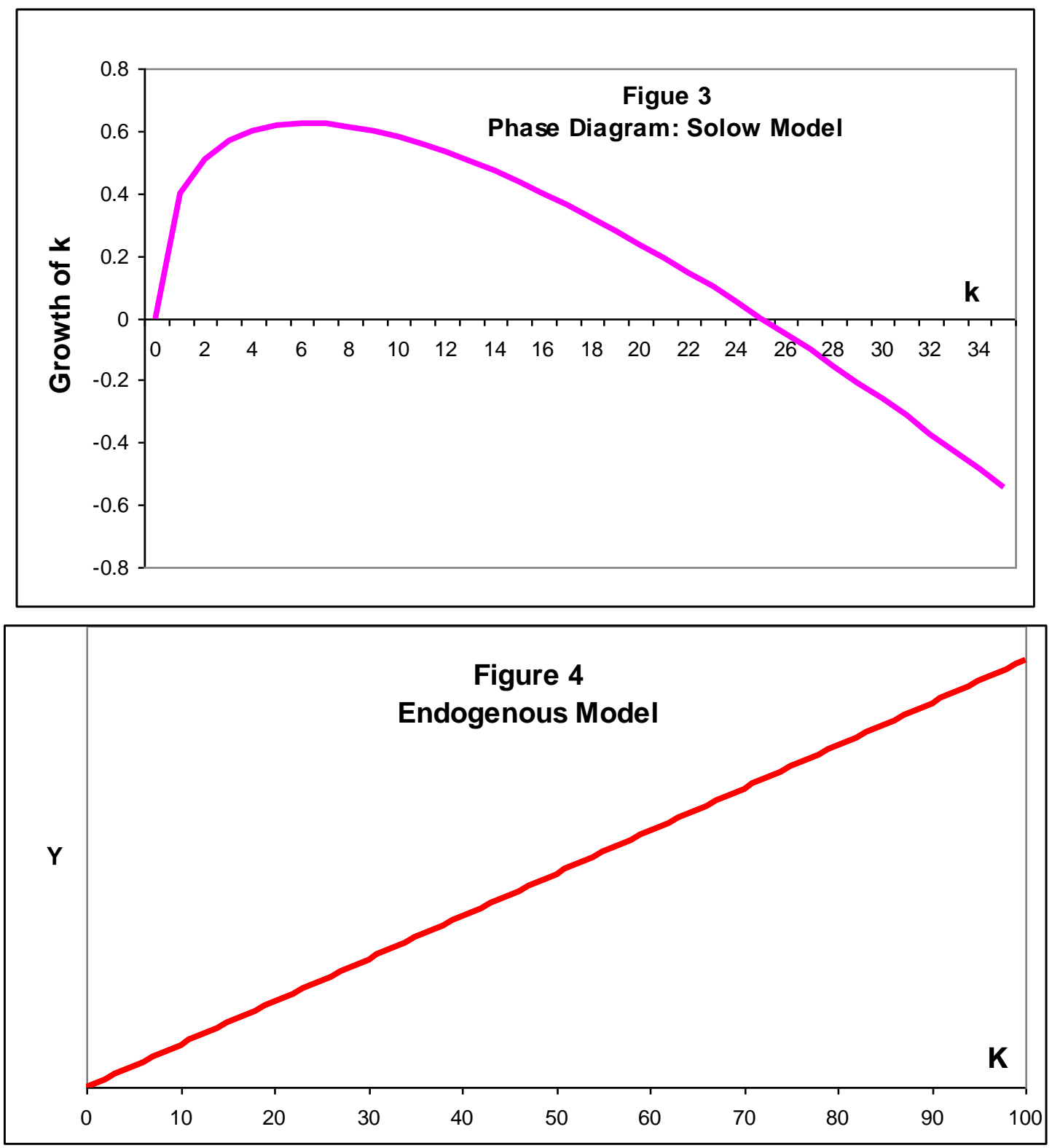


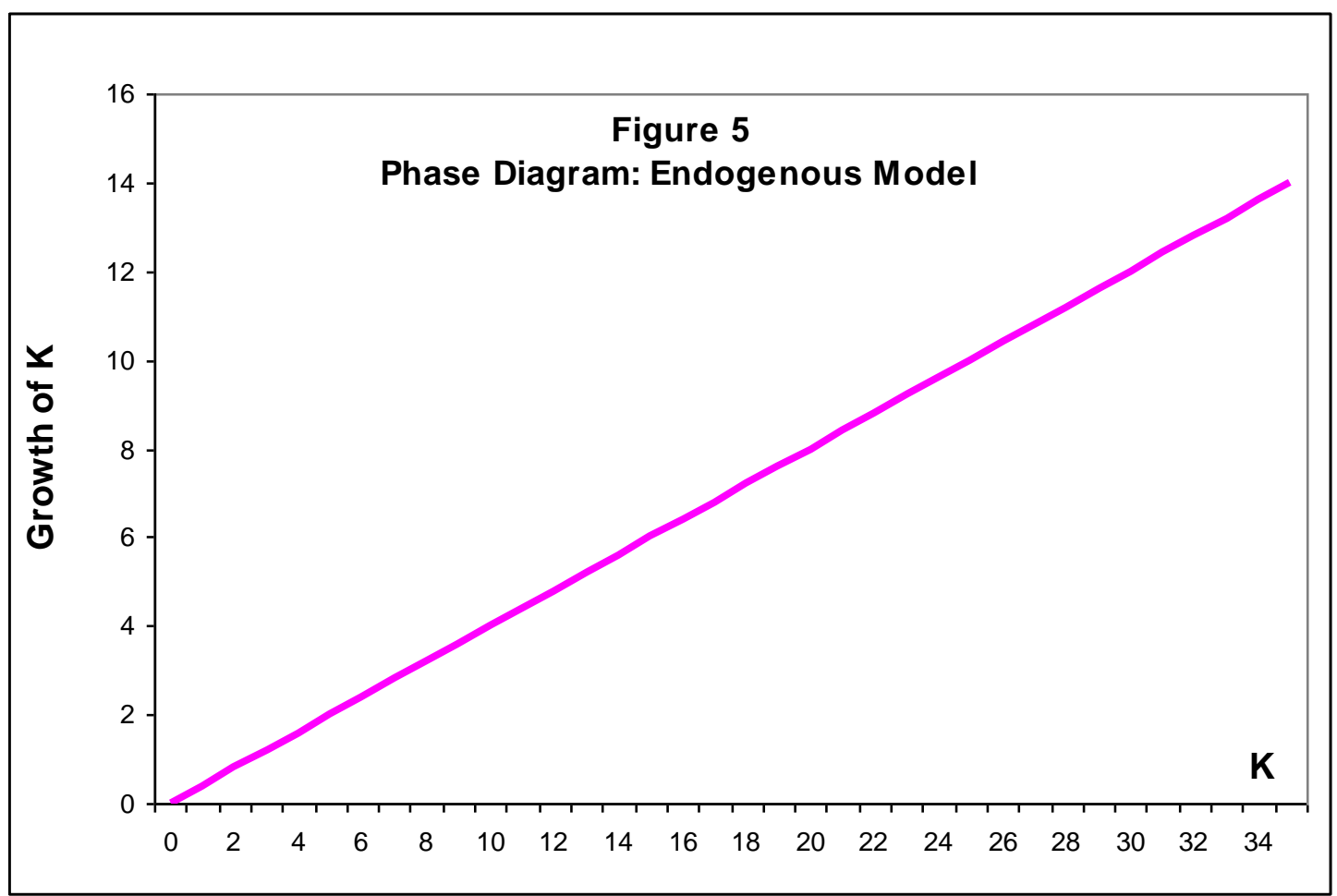


Table 1

Growth Model Exercise

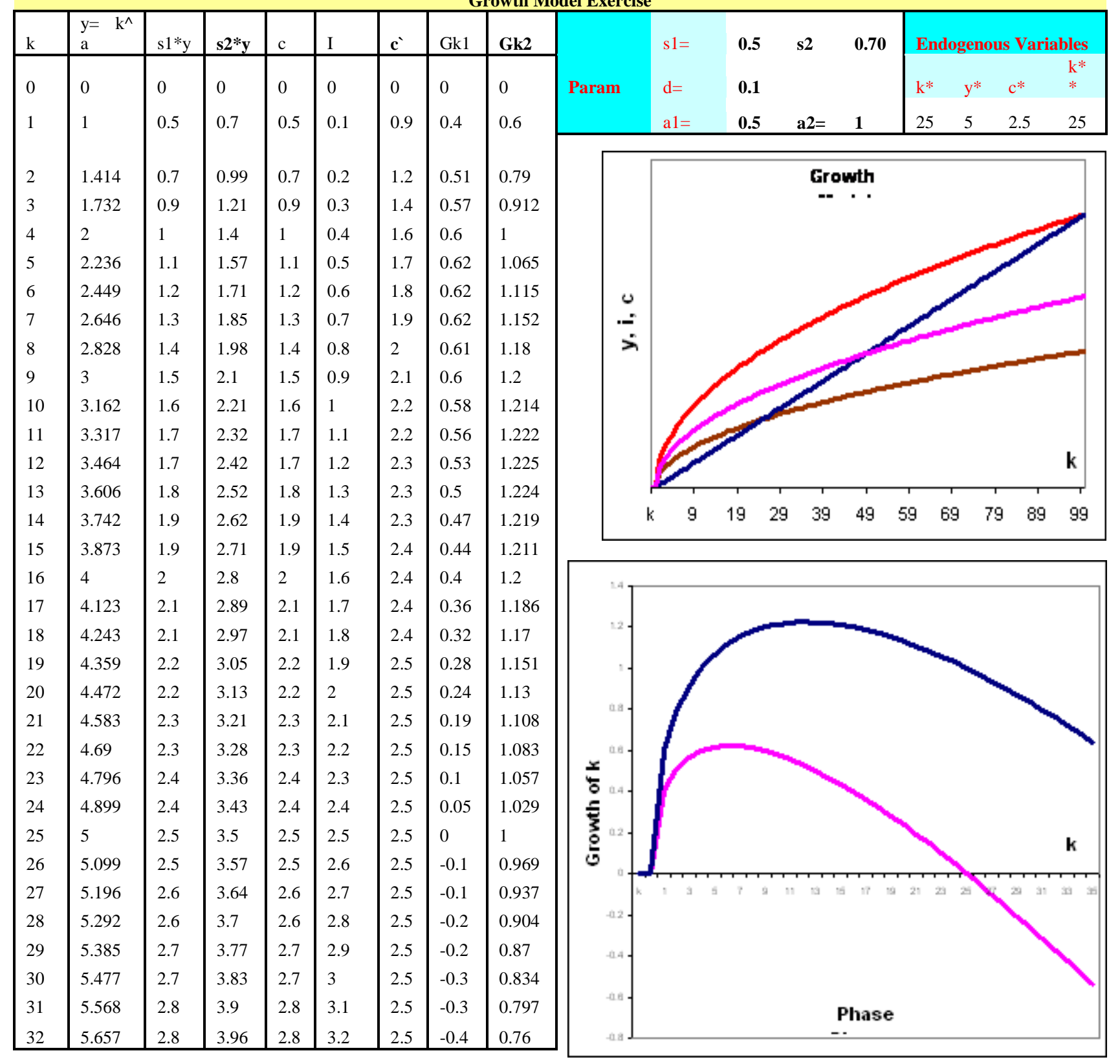

For detail and interaction go to: Model: Interactive http://www.busn.ucok.edu/mshaaf/Class\%20Exercise/solow.xls 


\section{AUTHOR INFORMATION}

Mohamad Shaaf has been a professor of economics at the University of Central Oklahoma since 1980. He has published in a variety of professional journals in different areas, including housing foreclosure, yield curve as a prediction of recession, stock market, role of exports in economic development, income distribution, OPEC's terms of trade, economics of crime, mergers and concentration, and the price of oil in dollars. In his research he has used a variety of models, including artificial intelligence, econometric methods, dynamic programming, portfolio theory, and mathematical modeling. He has taught political economy, monetary theory, macroeconomics, econometrics, fluctuation and stabilization, and mathematical economics.

\section{REFERENCES}

1. Aghion, P. (1994) "Endogenous Growth: a Schumpeterian Approach", in Endogenous Growth and Development, University of Siena.

2. Aghion, P. and Howitt, P. (1998) Endogenous Growth Theory, Cambridge, MA, MIT Press.

3. Arrow, K.J., H.B. Chenery, B.S. Minhas, and R.M. Solow (1961) "Capital-Labor Substitution and Economic Efficiency", Review of Economics and Statistics, 42, pp.225-250.

4. $\quad$ Domar, E. D. (1946) "Capital Expansion, Rate of Growth and Employment", Econometrica, 14, pp.137147.

5. $\quad$ Harrod, R. F. (1939) “An Essay in Dynamic Theory”, Economic Journal, 49, pp.14-33.

6. Inada, K. (1963) "On a Two-sector Model of Economic Growth: Comments and a Generalisation", Review of Economic Studies, 30, pp.119-127.

7. Mankiw, N. G. (2003) Macroeconomics. $5^{\text {th }}$ edition, Worth Publishers.

8. Rebelo, S. (1991) "Long-Run Policy Analysis and Long-Run Growth", Journal of Political Economy, 99, pp.500-521.

9. Romer, P.M. (1994) "The Origins of Endogenous Growth", Journal of Economic Perspectives, 8, pp.3-22.

10. Solow, R.M. (1956) "A Contribution to the Theory of economic Growth", Quarterly Journal of Economics, 70, pp.65-94.

11. Solow, R.M. (1957) "Technical Change and The Aggregate Production Function", Review of Economics and Statistics, 39, pp.312-320.

12. Solow, R.M. (1960) "Investment and Technological Progress", in Mathematical Methods in the Social Sciences 1959, eds. K. Arrow, S. Karlin and P. Suppes, pp.89-104, Stanford, Calif., Stanford University Press. 